\title{
Challenges toward applying UHTC-based composite coating on graphite substrate by spark plasma sintering
}

\author{
Mehran Jaberi Zamharir, Mohammad Zakeri*, Mansour Razavi \\ Ceramics Department, Materials and Energy Research Center, Karaj, Iran
}

\section{A B S T R A C T}

In this study, the UHTC-based composite layers were applied on the graphite substrates using the SPS method to protect them against ablation. The protective layers had some defects and problems such as crack, fracture, separation, melting, and weak adhesion to the substrate. Several factors such as the thickness of the composite layer, the number of protective layers, the SPS conditions (temperature, applied pressure, soaking time and mold), the chemical composition of the layers, the type of the substrate and the mismatch between the thermal expansion coefficients of the substrate and the applied layer(s) affected the quality and connection of the protective layer to the graphite substrate. The amount of additive materials influenced the melting phenomenon in the composite layer; for example, further $\mathrm{MoSi}_{2}$ in the layer led to more melting. The mismatch between the thermal expansion coefficients of the graphite substrate and the composite layer caused stresses during the cooling step, which resulted in cracks in the applied layer. Hence, proximity in the thermal expansion coefficients seems to be necessary for the formation of an acceptable adhesion between the layer and the substrate.

C 2021 The Authors. Published by Synsint Research Group.

\section{Introduction}

Carbon materials and carbon-carbon composites are important materials in various industries like supersonic spacecraft, furnace elements, turbine blades, rocket nozzles, and space shuttle noses. These materials are promising candidates for high temperature usages where high strength and resistance to wear are demanded [1-6]. Carbon materials have gained researcher's attention because of their ability to withstand temperatures above $2500{ }^{\circ} \mathrm{C}$ without cooling fluids, high elastic modulus, good resistance to abrasion and fatigue, good machinability, low density, and high tensile strength at temperatures above $1200{ }^{\circ} \mathrm{C}$ [7-10]. However, some limitations of these components are severe oxidation at temperatures above $400{ }^{\circ} \mathrm{C}$ in oxidizing atmosphere, as well as weight loss and properties degradation at high temperatures. Therefore, it is necessary to use a coating to prevent the oxidation of carbon substrates at $>400{ }^{\circ} \mathrm{C}$ [11-14].

\section{KEYWORDS}

Carbon materials

Spark plasma sintering

Ultrahigh temperature ceramics

Protective layer

Thermal expansion coefficient

* Corresponding author. E-mail address: m.zakeri@merc.ac.ir (M. Zakeri)

Received 20 September 2021; Received in revised form 20 December 2021; Accepted 20 December 2021.

Peer review under responsibility of Synsint Research Group. This is an open access article under the CC BY license (https://creativecommons.org/licenses/by/4.0/). https://doi.org/10.53063/synsint.2021.1452 
There are several techniques to create coatings with fine microstructure such as spray deposition, electroplating, electron beam irradiation, slurry coating, pack cementation, and chemical vapor deposition. Each method has special advantages to control the thickness of the coating and the composition of the material [25-29]. To create a reliable UHTC coating and to optimize the penetration and adhesion of the carbon-carbon composite, understanding of the physical and chemical properties of the coating materials is $[24,30]$.

Various methods can be used to create UHTC coatings. Among them, spark plasma sintering (SPS) is a modern effective method due to the proper connection of coating materials with the substrate, the ability to control the thickness of the coating, the high durability of coating, and the desirable thermomechanical properties. Such coatings with high density and good thickness can increase corrosion and abrasion resistance, improve toughness and prevent graphite oxidation [31-35].

Many efforts have been done to increase the oxidation resistance of diborides. These studies showed that the addition of $\mathrm{SiC}$ to $\mathrm{ZrB}_{2}$ greatly increases oxidation resistance at high temperatures [36-43]. Thermodynamic calculations of the oxidation of $\mathrm{ZrB}_{2}-\mathrm{SiC}$ composites showed that the formation of a SiC-rich layer, a $\mathrm{Zr}$-rich oxidized layer and a $\mathrm{SiC}$-depleted $\mathrm{ZrB}_{2}$ layer due to active oxidation of $\mathrm{SiC}$ decreased the oxidation rate [44]. In order to improve the oxidation resistance of carbon-carbon composites, a two-layer coating including $\mathrm{ZrB}_{2}$ and $\mathrm{SiC}$ was applied. First, slurries containing $\mathrm{ZrB}_{2}$ and $\mathrm{SiC}$ powders were prepared separately. Then, carbon-carbon composite samples were coated by squeeze infiltration in vacuum and heat-treated in argon atmosphere. The results showed that continuous multilayer coatings, including both $\mathrm{SiC}$ and $\mathrm{ZrB}_{2}$ phases, are required for the protection of the carbon/carbon substrate [45].

In another study, after surface preparation of carbon-carbon composites, $\mathrm{SiC}$ coating was applied by low pressure chemical vapor deposition (LPCVD) at $1200{ }^{\circ} \mathrm{C}$. Then, HfC-based coatings were deposited on SiC-coated samples at $1200{ }^{\circ} \mathrm{C}$ under atmospheric pressure. It should be noted that the precursor of the $\mathrm{SiC}$ coating was $\mathrm{CH}_{3} \mathrm{SiCl}_{3}$ and the precursors of the $\mathrm{HfC}$ coating were $\mathrm{C}_{3} \mathrm{H}_{6}$ and $\mathrm{HfCl}_{2}$ [46].

Pack cementation method at $2100-1900{ }^{\circ} \mathrm{C}$ for $2 \mathrm{~h}$ was used to prepare $\mathrm{ZrB}_{2}-\mathrm{SiC}$ coating on carbon/carbon composites in order to improve the erosion resistance. To increase the penetration rate, $\mathrm{ZrB}_{2}, \mathrm{Si}$, graphite and $\mathrm{Al}_{2} \mathrm{O}_{3}$ were chosen as the initial materials of the coating. During the pack cementation process, $\mathrm{Si}$ can react with the carbon/carbon composite to form $\mathrm{SiC}$. Then, $\mathrm{ZrB}_{2}-\mathrm{SiC}$ coating can be formed on the surface of carbon/carbon composites. Microstructural observations showed some microcracks on the surface of the coating due to the mismatch of thermal expansion coefficients between the coating and the carbon/carbon composite. The composite coating was dense without any infiltrative cracks or pores [47]. A multi-phase SiC-Si$\mathrm{ZrB}_{2}$ ceramic coating was applied on the surface of the SiC-coated carbon-carbon composite by powder pack cementation process. $\mathrm{SiC}$ bonding layer was formed on the surface of carbon-carbon composites using Si, $\mathrm{C}$ and $\mathrm{Al}_{2} \mathrm{O}_{3}$ powders at $1700-2000{ }^{\circ} \mathrm{C}$ for $2 \mathrm{~h}$ in argon atmosphere. Outer $\mathrm{SiC}-\mathrm{Si}-\mathrm{ZrB}_{2}$ coating was applied on the surface of $\mathrm{SiC}$-coated carbon-carbon composites at $1900-2200{ }^{\circ} \mathrm{C}$ for $2 \mathrm{~h}$ in an argon atmosphere using $\mathrm{Si}, \mathrm{B}_{2} \mathrm{O}_{3}$, graphite and $\mathrm{ZrB}_{2}$. The coating surface was dense and included microcracks that could be caused by rapid cooling to room temperature. The thickness of the coating was approximately $120 \mu \mathrm{m}$ without any cracks or pores. In addition, there were no cracks or gaps between the inner $\mathrm{SiC}$ and the outer $\mathrm{SiC}-\mathrm{Si}-$ $\mathrm{ZrB}_{2}$ coatings, indicating a suitable bonding [48].

A dense, well-bonded and crack-free $\mathrm{ZrB}_{2}-\mathrm{SiC}-\mathrm{WC}$ composite layer was applied on graphite substrate by SPS process at $1900{ }^{\circ} \mathrm{C}$ for $5 \mathrm{~min}$. Microstructural observations displayed three regions in the crosssection of the coating: the upper $\mathrm{ZrB}_{2}-\mathrm{SiC}-\mathrm{WC}$ coating, the substrate/coating interface and the diffusion bond. No crack in the coating/substrate interface was seen in the $\mathrm{ZrB}_{2}-\mathrm{SiC}-\mathrm{WC}$ coating [31]. In this research, the protective layers of ultrahigh temperature ceramics are applied on the graphite substrates by the SPS route to increase their resistance against oxidation and ablation. Challenges, problems and defects in this methodology are identified and discussed to help researchers to overcome potential limitations.

\section{Experimental procedure}

\subsection{Materials and methods}

The graphite substrates with a diameter of $30 \mathrm{~mm}$ and a thickness of 5 $\mathrm{mm}$ were cut from graphite blocks of two different materials. The characteristics of the Chinese (SB-1) and Japanese (TC-90) graphite substrates are given in Tables 1 and 2, respectively. Sandpaper No. 400 was used to prepare the surface of the graphite substrates in order to create a uniform surface. The graphite substrates were then cleaned by ethanol using an ultrasonic device and finally dried in an oven at 100 ${ }^{\circ} \mathrm{C}$ for $2 \mathrm{~h}$.

The specifications of the raw materials used in the composite protective layers are given in Table 3. Based on the design of experiments (Fig. 1), the raw material powders were weighed to prepare the composite mixtures. After that, the powders were ultrasonically mixed for $30 \mathrm{~min}$ in ethanol. Then, the obtained slurries were more mixed on a magnetic hot plate at $200{ }^{\circ} \mathrm{C}$ with a rate of $300 \mathrm{rpm}$. The prepared powder mixtures were completely dried in an oven at $100{ }^{\circ} \mathrm{C}$ for $24 \mathrm{~h}$. finally, the dried mixtures were passed through a 100 -mesh sieve to minimize agglomeration.

The graphite mold used in this research has a diameter of $60 \mathrm{~mm}$ containing a hole with a diameter of $30 \mathrm{~mm}$. The as-prepared powder mixtures were loaded on the graphite substrate embedded into the graphite mold, respectively. Then, the mold was placed inside the SPS furnace under vacuum conditions.

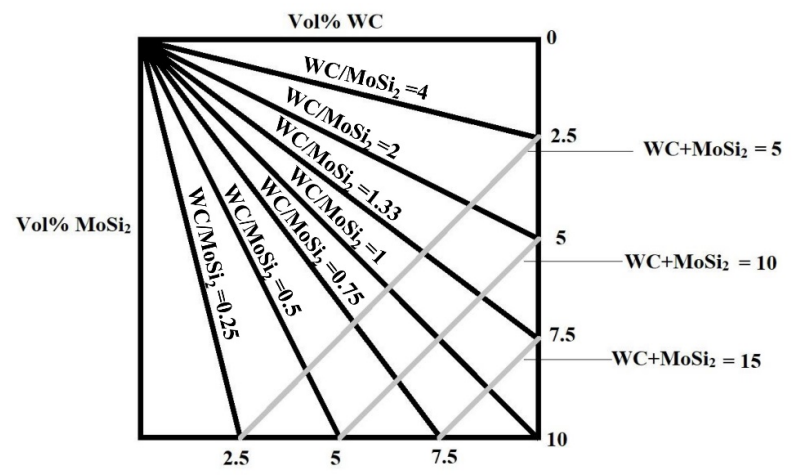

Fig. 1. Schematic of the compositional range of raw materials used for the outer composite layer. 
Table 1. Specifications of graphite substrate: type SB-1 (made in China).

\begin{tabular}{ccc}
\hline Property & Value & Unit \\
\hline Density & 1.74 & $\mathrm{~g} / \mathrm{cm}^{3}$ \\
\hline Porosity & 16 & $\%$ \\
\hline Bending strength & 40 & $\mathrm{MPa}$ \\
\hline Compressive strength & 85 & $\mathrm{MPa}$ \\
\hline $\begin{array}{c}\text { Thermal } \\
\text { conductivity }\end{array}$ & 120 & $\mathrm{~W} / \mathrm{mK}$ \\
\hline $\begin{array}{c}\text { Thermal expansion } \\
\text { coefficient }\end{array}$ & $4.6 \times 10^{-6}$ & ${ }^{\circ} \mathrm{C}^{-1}$ \\
\hline Elastic modulus & 11 & $\mathrm{GPa}$ \\
\hline Carbon content & $\sim 94$ & $\%$ \\
\hline
\end{tabular}

Table 2. Specifications of graphite substrate: type TC-90 (made in Japan).

\begin{tabular}{ccc}
\hline Property & Value & Unit \\
\hline Density & 1.80 & $\mathrm{~g} / \mathrm{cm}^{3}$ \\
\hline Hardness & 80 & Shore D \\
\hline Mean particle size & 5 & $\mu \mathrm{m}$ \\
\hline Specific resistance & 15 & $\mu \Omega \mathrm{m}$ \\
\hline Bending strength & 68 & $\mathrm{MPa}$ \\
\hline Tensile strength & 50 & $\mathrm{MPa}$ \\
\hline Compressive strength & 140 & $\mathrm{MPa}$ \\
\hline $\begin{array}{c}\text { Elastic modulus } \\
\text { Thermal expansion } \\
\text { coefficient }\end{array}$ & 12 & $\mathrm{GPa}$ \\
\hline $\begin{array}{c}\text { Thermal } \\
\text { conductivity }\end{array}$ & 110 & ${ }^{\circ} \mathrm{C}^{-1}$ \\
\hline $\begin{array}{c}\text { Volatile substances } \\
\text { (ash) }\end{array}$ & 200 & $\mathrm{~W} / \mathrm{mK}$ \\
\hline
\end{tabular}

Table 3. Specifications of raw material powders used in protective layers.

\begin{tabular}{cccc}
\hline Material & $\begin{array}{c}\text { Particle } \\
\text { size }(\boldsymbol{\mu m})\end{array}$ & $\begin{array}{c}\text { Purity } \\
(\mathbf{\%})\end{array}$ & Supplier \\
\hline $\mathrm{ZrB}_{2}$ & $1-3$ & 99.9 & Hongwu International Group Ltd. \\
\hline $\mathrm{SiC}$ & $1-10$ & 99.0 & Hongwu International Group Ltd. \\
\hline $\mathrm{MoSi}_{2}$ & $3-10$ & 99.5 & Hongwu International Group Ltd. \\
\hline $\mathrm{WC}$ & $5-15$ & 99.0 & Almaseh Saz Co. \\
\hline $\mathrm{Si}$ & $<12$ & 99.0 & Almaseh Saz Co. \\
\hline
\end{tabular}

Table 4. Chemical compositions of the outer composite layers chosen for the first methodology.

\begin{tabular}{ccccc}
\hline \multirow{2}{*}{$\begin{array}{c}\text { Sample } \\
\text { code }\end{array}$} & \multicolumn{5}{c}{$\begin{array}{c}\text { Composition } \\
\text { (vol\%) }\end{array}$} \\
\cline { 2 - 5 } & $\mathrm{MoSi}_{2}$ & $\mathrm{WC}$ & $\mathrm{SiC}$ & $\mathrm{ZrB}_{2}$ \\
\hline $\mathrm{Z}-1$ & 75 & 25 & 0 & 0 \\
\hline $\mathrm{Z}-2$ & 71.25 & 23.75 & 2.5 & 2.5 \\
\hline $\mathrm{Z}-3$ & 67.5 & 22.5 & 5 & 5 \\
\hline $\mathrm{Z}-4$ & 63.75 & 21.25 & 7.5 & 7.5 \\
\hline
\end{tabular}

\subsection{First methodology: double protective layers}

In the first methodology, double protective layers were applied on the graphite substrates (type SB-1), as schematically shown in Fig. 2. The chemical composition of the intermediate layer was $\mathrm{SiC}-30 \mathrm{vol} \% \mathrm{Si}$. The volume ratio of $\mathrm{ZrB}_{2} / \mathrm{SiC}$ in all outer composite layers was 3. The composition range of raw materials in the outer composite layer was considered based on the main diameter in Fig. $1\left(\mathrm{WC} / \mathrm{MoSi}_{2}=1\right)$. Hence, five points were selected as the powder chemical compositions of the outer composite layers (Table 4).

To investigate the effect of $\mathrm{Si}$ addition in the composition of the outer layer as well as the role of the thickness of the intermediate layer (or its exclusion) on the connection and the quality of the protective layer, a new series of experiments was designed and performed as described in Table 5. Table 6 shows the sintering conditions applied to all samples made with the first methodology.

Table 5. Specifications of the protective layers for another series of samples applied to the type SB-1 graphite substrates.

\begin{tabular}{|c|c|c|c|c|c|c|c|}
\hline \multirow{3}{*}{ ample code } & \multicolumn{4}{|c|}{ Outer layer } & \multicolumn{3}{|c|}{ Intermediate layer } \\
\hline & \multicolumn{3}{|c|}{$\begin{array}{c}\text { Composition } \\
\text { (vol\%) }\end{array}$} & \multirow[t]{2}{*}{$\begin{array}{c}\text { Thickness } \\
(\mu \mathrm{m})\end{array}$} & \multicolumn{2}{|c|}{$\begin{array}{c}\text { Composition } \\
\text { (vol\%) }\end{array}$} & \multirow[t]{2}{*}{$\begin{array}{c}\text { Thickness } \\
(\mu \mathrm{m})\end{array}$} \\
\hline & $\mathrm{Si}$ & $\mathrm{SiC}$ & $\mathrm{ZrB}_{2}$ & & $\mathrm{Si}$ & $\mathrm{SiC}$ & \\
\hline $\mathrm{T}-1$ & 15 & 15 & 70 & 700 & 50 & 50 & 300 \\
\hline $\mathrm{T}-2$ & - & 30 & 70 & 700 & 50 & 50 & 200 \\
\hline $\mathrm{T}-3$ & 15 & 15 & 70 & 700 & - & - & - \\
\hline
\end{tabular}


Table 6. The SPS conditions for applying the UHTC-based layers on the type SB-1 graphite substrates.

\begin{tabular}{cccc}
\hline $\begin{array}{c}\text { Dwell } \\
\text { time }\end{array}$ & $\begin{array}{c}\text { Final } \\
\text { temperature }\end{array}$ & $\begin{array}{c}\text { Final } \\
\text { pressure }\end{array}$ & $\begin{array}{c}\text { Initial } \\
\text { pressure }\end{array}$ \\
\hline $3 \mathrm{~min}$ & $1850^{\circ} \mathrm{C}$ & $25 \mathrm{MPa}$ & $10 \mathrm{MPa}$ \\
\hline
\end{tabular}

Table 7. Chemical compositions of the single protective layers considered for the second methodology.

\begin{tabular}{cccccc}
\hline \multirow{2}{*}{$\begin{array}{c}\text { Sample } \\
\text { code }\end{array}$} & \multicolumn{5}{c}{ Composition (vol\%) } \\
\cline { 2 - 6 } & $\mathrm{ZrB}_{2}$ & $\mathrm{SiC}$ & $\mathrm{Si}$ & $\mathrm{MoSi}_{2}$ & $\mathrm{WC}$ \\
\hline $\mathrm{M}-1$ & 70 & 15 & 15 & 0 & 0 \\
\hline $\mathrm{M}-2$ & 66.4 & 14.3 & 14.3 & 2.5 & 2.5 \\
\hline $\mathrm{M}-3$ & 62.94 & 13.53 & 13.53 & 5 & 5 \\
\hline
\end{tabular}

Table 8. The SPS conditions for applying the UHTC-based layers on the type TC-90 graphite substrates.

\begin{tabular}{|c|c|c|c|c|c|}
\hline \multirow{2}{*}{$\begin{array}{c}\text { Sample } \\
\text { code }\end{array}$} & \multicolumn{5}{|c|}{ SPS conditions } \\
\hline & Initial pressure & Final pressure & Final temperature & Dwell time at $1300^{\circ} \mathrm{C}$ & Dwell time at final temperature \\
\hline M-1 & $10 \mathrm{MPa}$ & $25 \mathrm{MPa}$ & $1950^{\circ} \mathrm{C}$ & $5 \mathrm{~min}$ & $10 \mathrm{~min}$ \\
\hline M-2 & $10 \mathrm{MPa}$ & $25 \mathrm{MPa}$ & $1950^{\circ} \mathrm{C}$ & $5 \mathrm{~min}$ & $10 \mathrm{~min}$ \\
\hline M-3 & $10 \mathrm{MPa}$ & $25 \mathrm{MPa}$ & $1950^{\circ} \mathrm{C}$ & $5 \mathrm{~min}$ & $10 \mathrm{~min}$ \\
\hline M-2(2) & $10 \mathrm{MPa}$ & $25 \mathrm{MPa}$ & $1872^{\circ} \mathrm{C}$ & $5 \mathrm{~min}$ & $10 \mathrm{~min}$ \\
\hline M-2(3) & $10 \mathrm{MPa}$ & $25 \mathrm{MPa}$ & $1840^{\circ} \mathrm{C}$ & $5 \mathrm{~min}$ & $5 \mathrm{~min}$ \\
\hline
\end{tabular}

\subsection{Second methodology: single protective layers}

In this methodology, single protective layers were applied on the graphite substrates (type TC-90), as schematically displayed in Fig. 3. The volume ratio of $\mathrm{ZrB}_{2} / \mathrm{SiC}+\mathrm{Si}$ in the composite layer was considered approximately 2.33 . The composition range of the raw materials was also selected based on the main diameter in Fig. 1 (WC/MoSi $2=1$ ). The compositions of the chosen powder mixtures are presented in Table 7.

The sintering conditions used for the formation of the single protective layers are given in Table 8. It should be noted that to achieve better results and optimize processing variables, some single protective layers were applied to the M-2 sample at lower SPS temperatures and dwell times.

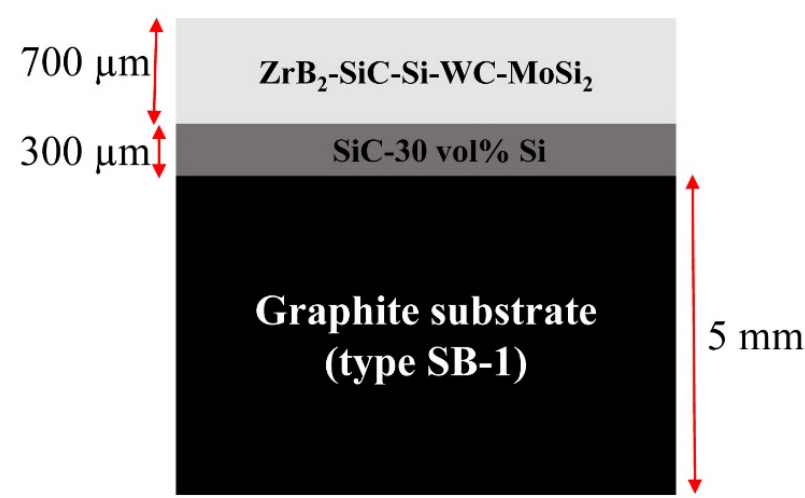

Fig. 2. Schematic of the arrangement of the double protective layers on the type SB-1 graphite substrates.

\section{Results and discussion}

\subsection{Challenges of applying double protective layers}

The protective layers studied in this section have been applied by SPS technology on the type SB-1 graphite substrates. Fig. 4 shows the optical microscopy images of the surface of the double protective layer of the Z-1 sample. Cracks and separations can be observed on the surface of the composite layer. Such defects are mainly caused by stresses during cooling rapid cooling of the sample due to the mismatch of the thermal expansion coefficients of the graphite substrate with the UHTC-based composite layers. Inadequate thickness of the intermediate layer can be mentioned as another reason for these defects.

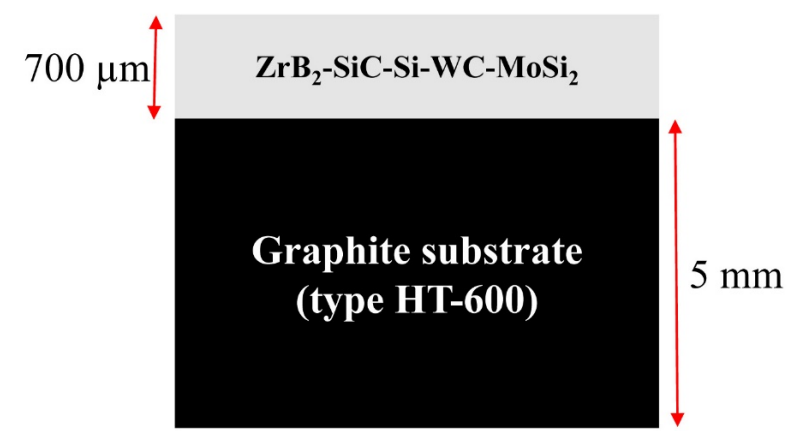

Fig. 3. Schematic of the arrangement of the single protective layers on the type TC-90 graphite substrates. 

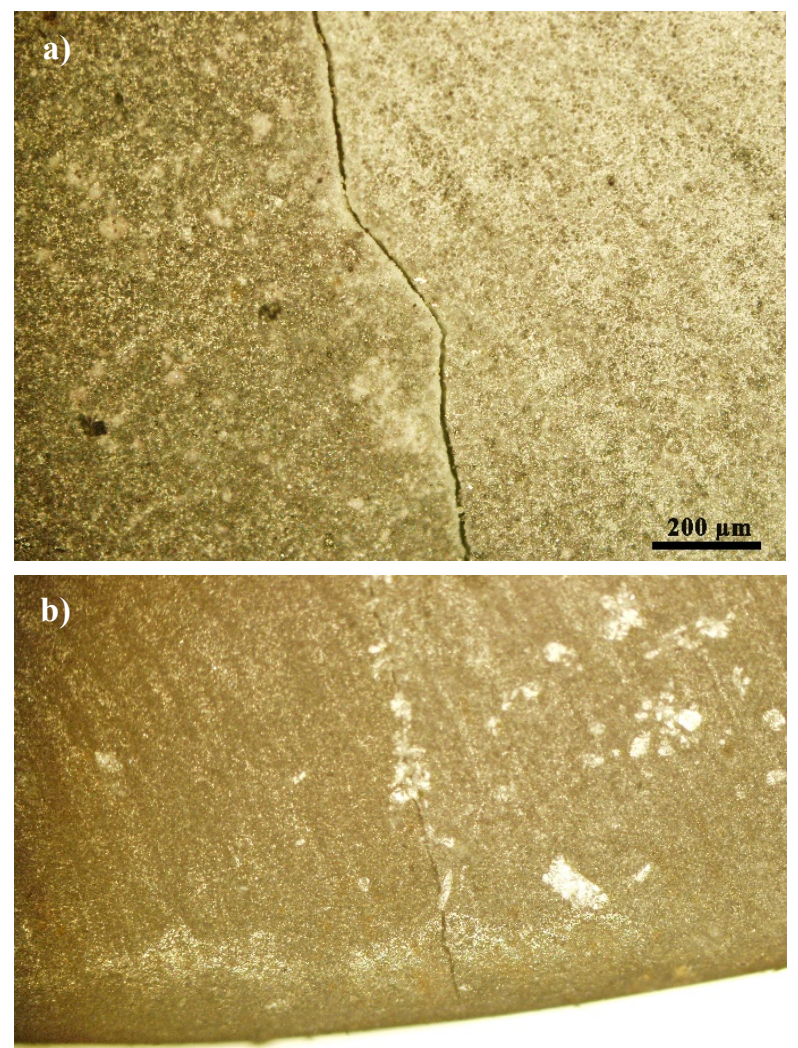

$500 \mu \mathrm{m}$

Fig. 4. Optical microscopy images of the surface of the double protective layer of the Z-1 sample.

Fig. 5 shows the macroscopic images of the surfaces of the Z-2, Z-3 and Z-4 samples. As it can be seen, the outer composite layers do not have a proper connection with the intermediate layers and the graphite substrates. This problem may be occurred owing to the following reasons:

-Mismatch between the thermal expansions coefficients of the composite layers and the graphite substrate.

-Inappropriate SPS conditions (temperature, dwell time and/or applied pressure).

-Insufficient thickness of the intermediate layer.

-Inappropriate chemical composition of the intermediate and/or the outer layers.

As seen in the macroscopic image of the surface of the T-1 sample (Fig. 6), despite the changes in the chemical composition of the outer layer (addition of $\mathrm{Si}$ ) and the intermediate layer, the double protective layer is not properly bonded and it is separated from the graphite substrate. Optical microscopy images of the surface and the crosssection of the central part of the T-1 sample are shown in Fig. 7. The applied layers are peeled off at the edges of the sample, but the central area is relatively connected to the substrate. Therefore, the strategy of adding $\mathrm{Si}$ to the outer layer and increasing its amount in the intermediate layer did not have an interesting result.

Fig. 8 shows a macroscopic image of the protective layer applied to the T-2 sample. Here, the thickness of the intermediate layer was decreased from 300 to $200 \mu \mathrm{m}$ to reduce the effect of thickness on the mismatch
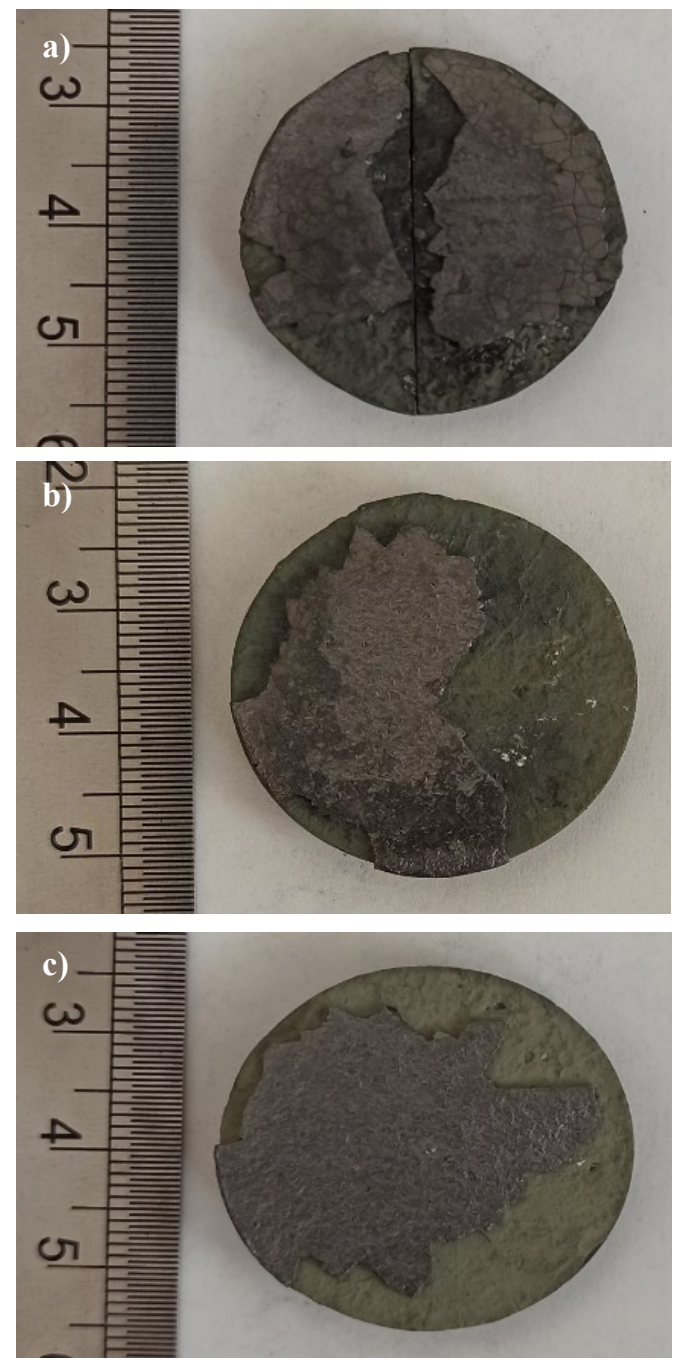

Fig. 5. Macroscopic images of the double protective layers of the a) Z-2, b) Z-3, and c) Z-4 samples.

in coefficients of thermal expansion of the applied layer with the graphite substrate. There are many cracks on the surface that separated the protective layers from the edges of the sample. Hence, reducing the thickness of the intermediate layer did not have a tangible effect on improving the bonding of the applied layer.

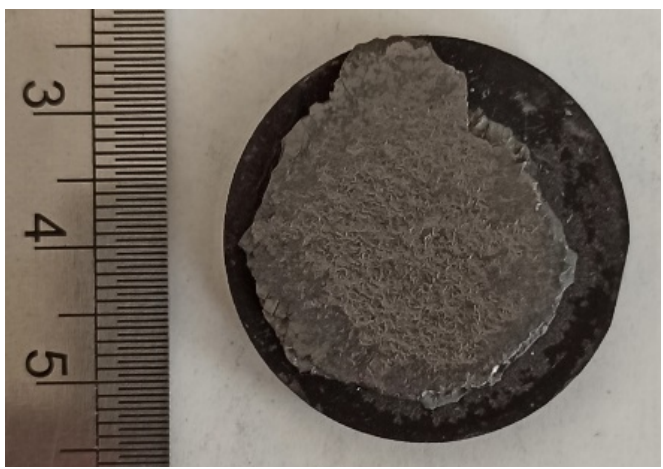

Fig. 6. Macroscopic image of the double protective layer of the T-1 sample. 

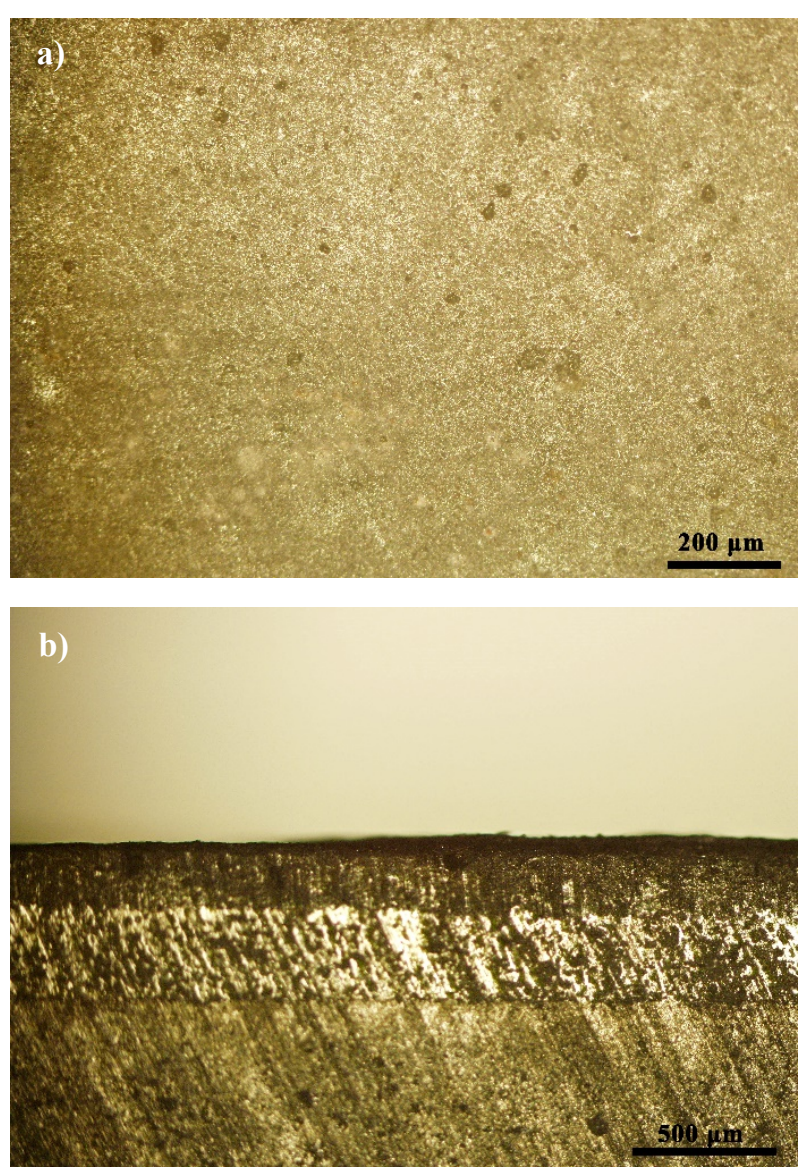

Fig. 7. Optical microscopy image of a) the surface and b) the crosssection of the central part of the T-1 sample.

A macroscopic image of the protective layer applied to the T-3 sample is presented in Fig. 9. It should be noted that in this sample, the intermediate layer was eliminated from its design of experiment, but the outer layer contained Si additive. On one hand, there are many long and short cracks on the surface. On the other hand, non-uniformity on the surface of the applied composite layer is also visible, may be due to the surface melting.

In addition to the above-mentioned efforts, changes were made in the SPS process parameters, which can be listed as follows:

-Reducing the number of graphite foils used between the sample and the mold.

-Changing the electrical current and the maximum temperature.

-Changing the dwell time at maximum temperature.

-Holding at $1300{ }^{\circ} \mathrm{C}$ for $5 \mathrm{~min}$.

-Applying maximum pressure at $1800{ }^{\circ} \mathrm{C}$ before reaching the final temperature.

Unfortunately, none of the new SPS conditions had a positive effect on the adhesion of the composite layer to the graphite substrate as the applied layers contained cracks and were separated from the substrate in some parts. Therefore, based on the observations in the first methodology, it seems that the changes in the chemical composition and the thickness of the applied layer, removal of the intermediate layer and changes in the SPS process conditions have not greatly improved the quality of the protective layer created on the type SB-1 graphite substrate. Therefore, due to the fact that several effective factors were

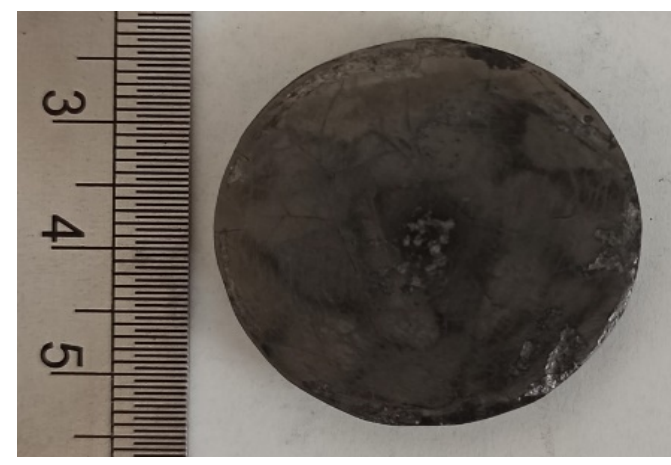

Fig. 8. Macroscopic image of the double protective layer of the T-2 sample.

investigated but no acceptable result was obtained, it is likely that there is a problem with the substrate material, actually with its thermal expansion coefficient.

\subsection{Challenges of applying single protective layers}

The single protective layers investigated in this section have been applied by the SPS route on the TC-90 graphite substrates. Fig. 10 shows the macroscopic images of the surfaces of the M-1, M-2 and M3 samples. As it can be clearly seen, there is a kind of melting in the center of the composite layers. It seems that the temperature in the center of the samples was higher than the edges, which may be due to the high applied current and the electrical/thermal conductivity of $\mathrm{MoSi}_{2}$ [49]. The presence of many cracks in the surrounding areas, the edges of the samples, indicates that the sintering process has not been completed and due to the low temperature in these areas, proper connections between the graphite substrates and the composite layers have not been established. It appears that these cracks occurred during the samples cooling step, due to the mismatch of the thermal expansion coefficients between the substrates and the applied layers. Considering that the thermal expansion coefficients of $\mathrm{ZrB}_{2}, \mathrm{SiC}, \mathrm{Si}, \mathrm{WC}, \mathrm{MoSi}_{2}$ and TC-90 graphite are $6.6 \times 10^{-6}[47], 5 \times 10^{-6}[47], 2.5 \times 10^{-6}[50]$, $5.2 \times 10^{-6}[51], 8.1 \times 10^{-6}[52]$ and $5 \times 10^{-6} \mathrm{~K}^{-1}$, respectively, the mismatch between the applied protective layers with the graphite substrates may lead to cracking, separation or even delamination of the coating [46]. A comparison of the macroscopic images shown in Fig. 10 indicates

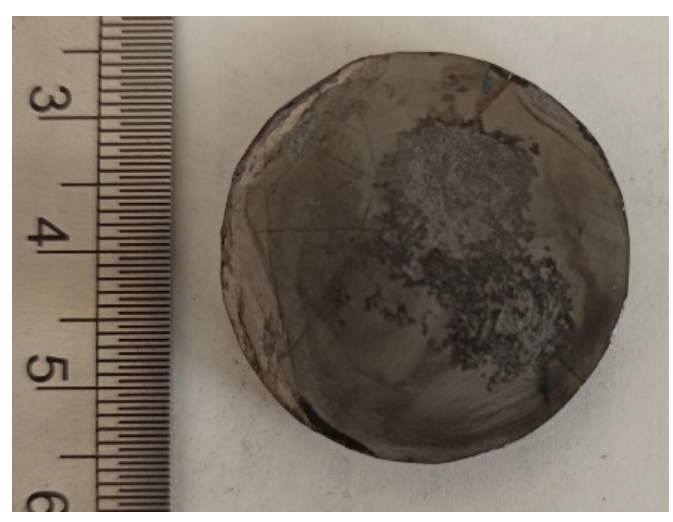

Fig. 9. Macroscopic image of the single protective layer of the T-3 sample. 
that the M-3 sample includes more melting in the central zone than the M-2 sample, due to its more $\mathrm{MoSi}_{2}$ content. It is found that unlike the M-2 sample that has short cracks, the M-3 sample has long and deep cracks that extend from the center to the edges of the sample. The presence of a thermal gradient between the center and surrounding areas can also be assumed, which causes stress and subsequently creates cracks. The optical microscopy images of the interface of melted/non-melted areas and the cross-section of the melted zone in the M-2 sample are shown in Fig. 11.

In order to solve the above-mentioned defects, which are probably due to the high temperature (high applied current) and the concentration of the current in the center of the samples, new composite layers were applied to the type TC-90 graphite substrates under milder SPS conditions (lower applied current and shorter dwell time). The macroscopic images of these new samples (M-2(2) and M-2(3)) are shown in Fig. 12. Compared to the observations of sample M-2 (Fig. $10 \mathrm{~b}$ ), the melting defects and the number of cracks are decreased by
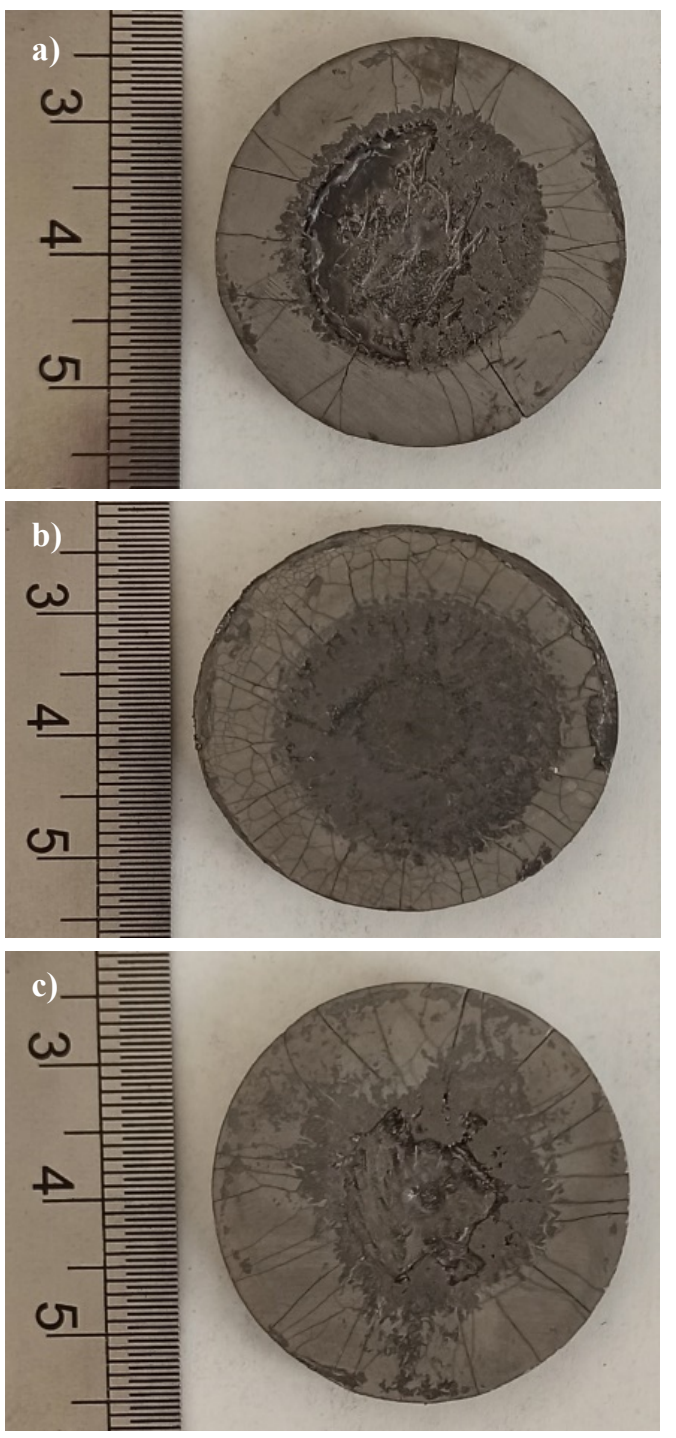

Fig. 10. Macroscopic images of the single protective layers of the a) M1, b) M-2 and c) M-3 samples.
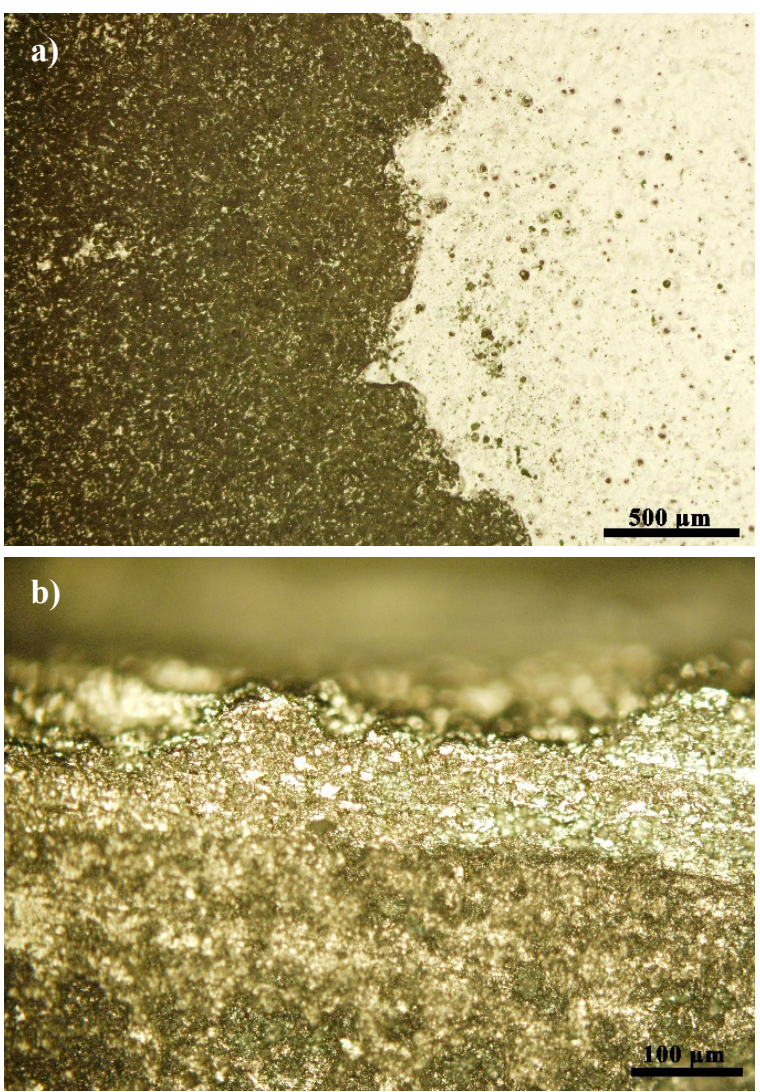

Fig. 11. Optical microscopy images of a) the interface of melted/nonmelted areas and b) the cross-section of the melted zone in the M-2 sample.
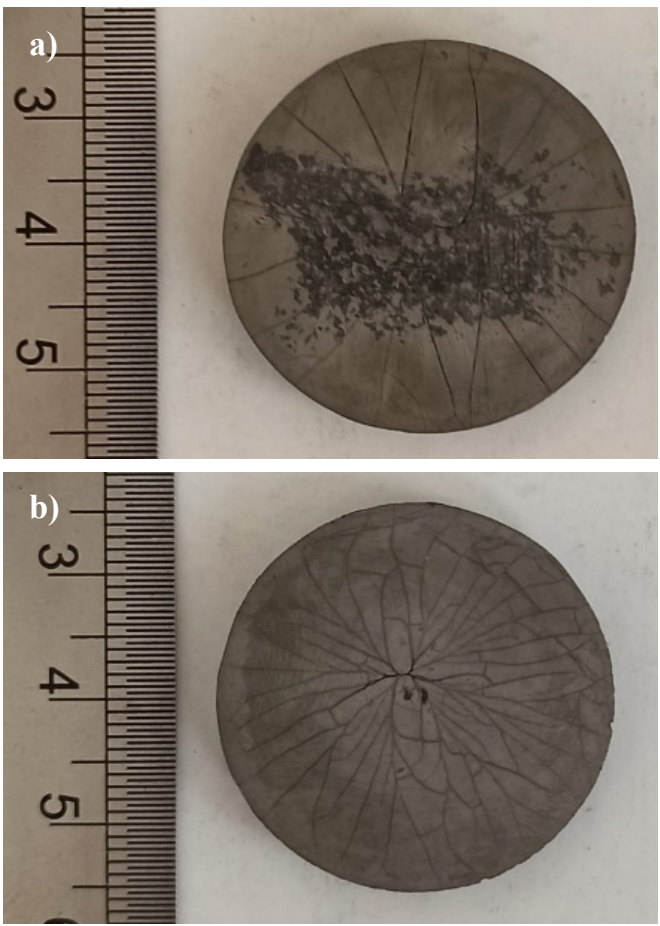

Fig. 12. Macroscopic images of the single protective layers of the a) M-2(2) and b) M-2 (3) samples. 
moderating the sintering conditions. Although the melting defect in the center of the applied layer can be eliminated by adjusting the SPS conditions, some cracks are still observed on the surface of the applied layers. However, the authors of this paper will continue to research in this field and if better results are obtained, we will publish them in the future.

\section{Conclusions}

In this study, challenges of applying protective UHTC-based composite layers on the graphite substrates using the SPS method were studied. Based on the observations, the layers applied on the graphite had many problems such as cracks, separation, weak adhesion, and melting. The results showed that several factors affect the connection of the protective composite layer to the graphite substrate. The most important factor was the mismatch between the thermal expansion coefficients of the graphite substrate and the applied composite layer.

\section{References}

[1] Z. Dong, B. Sun, H. Zhu, G. Yuan, B. Li, J. Guo, X. Li, Y. Cong, J. Zhang, A review of aligned carbon nanotube arrays and carbon/carbon composites: fabrication, thermal conduction properties and applications in thermal management, New Carbon Mater. 36 (2021) 873-892. https://doi.org/10.1016/S18725805(21)60090-2.

[2] J.D. Webster, M.E. Westwood, F.H. Hayes, R.J. Day, R. Taylor, A. Duran, M. Aparicio, K. Rebstock, W.D. Vogel, Oxidation Protection Coatings for $\mathrm{C} / \mathrm{SiC}$ based on Yttrium Silicate, J. Eur. Ceram. Soc. 18 (1998) 2345-2350. https://doi.org/10.1016/S0955-2219(98)00241-6.

[3] S.M. Gee, J.A. Little, Oxidation behaviour and protection of carbon/carbon composites, J. Mater. Sci. 26 (1991) 1093-1100. https://doi.org/10.1007/BF00576792.

[4] S. Chen, X. Qiu, B. Zhang, J. Xu, F. Zhong, B. Zhu, Y. Zhang, J. Ou-Yang, X. Yang, Advances in antioxidation coating materials for carbon/carbon composites, J. Alloys Compd. 886 (2021) 161143. https://doi.org/10.1016/j.jallcom.2021.161143.

[5] T. Cheng, Understanding the ultra-high-temperature mechanical behaviors of advanced two-dimensional carbon-carbon composites, Ceram. Int. 46 (2020) 21395-21401. https://doi.org/10.1016/j.ceramint.2020.05.237.

[6] J.H. Kim, A.Y. Jo, Y.J. Choi, K.B. Lee, J.S. Im, B.C. Bai, Improving the mechanical strength of carbon-carbon composites by oxidative stabilization, J. Mater. Res. Technol. 9 (2020) 16513-16521. https://doi.org/10.1016/j.jmrt.2020.11.064.

[7] J. Wang, X. Zhang, Z. Li, Y. Ma, L. Ma, Recent progress of biomass-derived carbon materials for supercapacitors, J. Power Sources. 451 (2020) 227794.

https://doi.org/10.1016/j.jpowsour.2020.227794.

[8] E. Fitzer, L.M. Manocha, Carbon Reinforcements and Carbon/Carbon Composites, Springer Berlin Heidelberg, Berlin, Heidelberg, 1998. https://doi.org/10.1007/978-3-642-58745-0.

[9] B.D. Agarwal, L.J. Broutman, C.W. Bert, Analysis and Performance of Fiber Composites, J. Appl. Mech. 48 (1981) 213-213. https://doi.org/10.1115/1.3157582.

[10] D.E. Wittmer, M.Z. Temuri, Thermochemical Studies in Selected Metal-Carbon-Oxygen Systems, J. Am. Ceram. Soc. 74 (1991) 973 982. https://doi.org/10.1111/j.1151-2916.1991.tb04330.x.

[11]A. Tyagi, R.S. Walia, Q. Murtaza, S.M. Pandey, P.K. Tyagi, B. Bajaj, A critical review of diamond like carbon coating for wear resistance applications, Int. J. Refract. Met. Hard Mater. 78 (2019) 107-122. https://doi.org/10.1016/j.ijrmhm.2018.09.006.

[12] P. Wang, M. Tong, H. Wang, H. Li, Y. Jia, B. Li, Y. Zhang, Z. Zhao, Gradient HfB2-SiC multilayer oxidation resistant coating for $\mathrm{C} / \mathrm{C}$ composites, Ceram. Int. 44 (2018) 20968-20973. https://doi.org/10.1016/j.ceramint.2018.08.104.

[13] R.V. Krishnarao, M.Z. Alam, D.K. Das, In-situ formation of SiC, $\mathrm{ZrB2}-\mathrm{SiC}$ and $\mathrm{ZrB} 2-\mathrm{SiC}-\mathrm{B} 4 \mathrm{C}-\mathrm{YAG}$ coatings for high temperature oxidation protection of C/C composites, Corros. Sci. 141 (2018) 7280. https://doi.org/10.1016/j.corsci.2018.07.002.

[14] Q. Fu, P. Zhang, L. Zhuang, L. Zhou, J. Zhang, J. Wang, X. Hou, R. Riedel, H. Li, Micro/nano multiscale reinforcing strategies toward extreme high-temperature applications: Take carbon/carbon composites and their coatings as the examples, J. Mater. Sci. Technol. 96 (2022) 31-68. https://doi.org/10.1016/j.jmst.2021.03.076.

[15] X. Jin, X. Fan, C. Lu, T. Wang, Advances in oxidation and ablation resistance of high and ultra-high temperature ceramics modified or coated carbon/carbon composites, J. Eur. Ceram. Soc. 38 (2018) 128. https://doi.org/10.1016/j.jeurceramsoc.2017.08.013.

[16] Y. Jiang, T. Liu, H. Ru, W. Wang, C. Zhang, X. Yue, Oxidation and ablation protection of double layer $\mathrm{HfB} 2-\mathrm{SiC}-\mathrm{Si} / \mathrm{SiC}-\mathrm{Si}$ coating for graphite materials, J. Alloys Compd. 782 (2019) 761-771. https://doi.org/10.1016/j.jallcom.2018.12.256.

[17] S. Fan, X. Ma, Z. Li, J. Hu, Z. Xie, J. Deng, L. Zhang, L. Cheng, Design and optimization of oxidation resistant coating for $\mathrm{C} / \mathrm{C}$ aircraft brake materials, Ceram. Int. 44 (2018) 175-182. https://doi.org/10.1016/j.ceramint.2017.09.156.

[18] N.S. Peighambardoust, Ç. Çevik, T. Assar, S. Jung, S.Y. Lee, J.H. Cha, Pulsed electric current sintering of TiB2-based ceramics using nitride additives, Synth. Sinter. 1 (2021) 28-33. https://oi.org/10.53063/synsint.2021.1112.

[19] S. Jafargholinejad, S. Soleymani, Effects of carbon nano-additives on characteristics of $\mathrm{TiC}$ ceramics prepared by field-assisted sintering, Synth. Sinter. 1 (2021) 62-68. https://doi.org/10.53063/synsint.2021.1123.

[20] Z. Balak, M. Zakeri, M. Rahimipour, E. Salahi, Taguchi design and hardness optimization of ZrB2-based composites reinforced with chopped carbon fiber and different additives and prepared by SPS, J. Alloys Compd. 639 (2015) 617-625. https://doi.org/10.1016/j.jallcom.2015.03.131.

[21] F. Sadegh Moghanlou, M. Vajdi, M. Sakkaki, S. Azizi, Effect of graphite die geometry on energy consumption during spark plasma sintering of zirconium diboride, Synth. Sinter. 1 (2021) 54-61. https://doi.org/10.53063/synsint.2021.117.

[22] W.G. Fahrenholtz, G.E. Hilmas, I.G. Talmy, J.A. Zaykoski, Refractory Diborides of Zirconium and Hafnium, J. Am. Ceram. Soc. 90 (2007) 1347-1364. https://doi.org/10.1111/j.15512916.2007.01583.x.

[23]Z. Bahararjmand, M.A. Khalilzadeh, F. Saberi-Movahed, T.H. Lee, J. Wang, S. Lee, H.W. Jang, Role of Si3N4 on microstructure and hardness of hot-pressed ZrB2-SiC composites, Synth. Sinter. 1 (2021) 34-40. https://doi.org/10.53063/synsint.2021.1113.

[24] E.L. Corral, R.E. Loehman, Ultra-High-Temperature Ceramic Coatings for Oxidation Protection of Carbon-Carbon Composites, J. Am. Ceram. Soc. 91 (2008) 1495-1502. https://doi.org/10.1111/j.1551-2916.2008.02331.x.

[25] P. Panjan, A. Drnovšek, P. Gselman, M. Čekada, M. Panjan, Review of Growth Defects in Thin Films Prepared by PVD Techniques, Coatings. 10 (2020) 447. https://doi.org/10.3390/coatings10050447.

[26] H. Aghajani, M. Roostaei, S. Sharif Javaherian, A. Taghizadeh Tabrizi, A. Abdoli Silabi, N. Farzam Mehr, Wear behavior of selfpropagating high-temperature synthesized $\mathrm{Cu}-\mathrm{TiO} 2$ nanocomposites, Synth. Sinter. 1 (2021) 127-134. https://doi.org/10.53063/synsint.2021.1332.

[27] A. Zakeri, M.R. Masoumi Balashadehi, A. Sabour Rouh Aghdam, Development of hybrid electrodeposition/slurry diffusion aluminide coatings on Ni-based superalloy with enhanced hot corrosion resistance, J. Compos. Compd. 2 (2021) 1-8. https://doi.org/10.52547/jcc.3.1.1.

[28] J. Dong, Y. Sun, F. He, H. Huang, J. Zhen, Effects of substrate surface roughness and aluminizing agent composition on the 
aluminide coatings by low-temperature pack cementation, Mater. Res. Express. 6 (2018) 036409. https://doi.org/10.1088/20531591/aaf586.

[29] S. Karimi, S.M. Arab, S.R. Hosseini Zeidabadi, S. Javadpour, Tribological behavior and mechanical properties of friction stir processed HDPE/Fe-Fe3O4 composites, Synth. Sinter. 1 (2021). https://doi.org/10.53063/synsint.2021.1350.

[30] M. Abdolahpour Salari, G. Merhan Muğlu, M. Rezaei, M. Saravana Kumar, H. Pulikkalparambil, S. Siengchin, In-situ synthesis of TiN and $\mathrm{TiB} 2$ compounds during reactive spark plasma sintering of $\mathrm{BN}-$ Ti composites, Synth. Sinter. 1 (2021) 48-53 . https://doi.org/10.53063/synsint.2021.119.

[31] M. Shirani, M. Rahimipour, M. Zakeri, S. Safi, T. Ebadzadeh, ZrB2SiC-WC coating with $\mathrm{SiC}$ diffusion bond coat on graphite by spark plasma sintering process, Ceram. Int. 43 (2017) 14517-14520. https://doi.org/10.1016/j.ceramint.2017.07.123.

[32] K.-T. Wang, L.-Y. Cao, J.-F. Huang, J. Fei, A mullite/SiC oxidation protective coating for carbon/carbon composites, J. Eur. Ceram. Soc. 33 (2013) 191-198. https://doi.org/10.1016/j.jeurceramsoc.2012.08.009.

[33] S.A.A. Shalmani, M. Sobhani, O. Mirzaee, M. Zakeri, Ablation resistance of graphite coated by spark plasma sintered ZrB2-SiC based composites, Boletín La Soc. Española Cerámica y Vidr. (2021). https://doi.org/10.1016/j.bsecv.2021.05.004.

[34] Y. Miao, X. Wang, Y. Cheng, Carbon nanotube/titanium carbide solgel coated zirconium diboride composites prepared by spark plasma sintering, Ceram. Int. 44 (2018) 19262-19267. https://doi.org/10.1016/j.ceramint.2018.07.151.

[35] S.A. Akbarpour Shalmani, M. Sobhani, O. Mirzaee, M. Zakeri, Effect of $\mathrm{HfB} 2$ and WC additives on the ablation resistance of $\mathrm{ZrB} 2$ $\mathrm{SiC}$ composite coating manufactured by SPS, Ceram. Int. 46 (2020) 25106-25112. https://doi.org/10.1016/j.ceramint.2020.06.297.

[36] M. Ghassemi Kakroudi, M. Dehghanzadeh Alvari, M. Shahedi Asl, N. Pourmohammadie Vafa, T. Rabizadeh, Hot pressing and oxidation behavior of $\mathrm{ZrB} 2-\mathrm{SiC}-\mathrm{TaC}$ composites, Ceram. Int. 46 (2020) 3725-3730. https://doi.org/10.1016/j.ceramint.2019.10.093.

[37] S. Haghgooye Shafagh, S. Jafargholinejad, S. Javadian, Beneficial effect of low BN additive on densification and mechanical properties of hot-pressed ZrB2-SiC composites, Synth. Sinter. 1 (2021) 69-75. https://doi.org/10.53063/synsint.2021.1224.

[38] F. Sadegh Moghanlou, M. Vajdi, H. Jafarzadeh, Z. Ahmadi, A. Motallebzadeh, F. Sharifianjazi, M. Shahedi Asl, M. Mohammadi, Spark plasma sinterability and thermal diffusivity of TiN ceramics with graphene additive, Ceram. Int. 47 (2021) 10057-10062. https://doi.org/10.1016/j.ceramint.2020.12.152.

[39] L. He, Y. Sun, Q. Meng, B. Liu, J. Wu, X. Zhang, Enhanced oxidation properties of $\mathrm{ZrB} 2-\mathrm{SiC}$ composite with short carbon fibers at $1600^{\circ} \mathrm{C}$, Ceram. Int. 47 (2021) 15483-15490. https://doi.org/10.1016/j.ceramint.2021.02.114.

[40] M. Dehghanzadeh Alvari, M. Ghassemi Kakroudi, B. Salahimehr, R. Alaghmandfard, M. Shahedi Asl, M. Mohammadi, Microstructure, mechanical properties, and oxidation behavior of hot-pressed $\mathrm{ZrB2}-$ SiC-B4C composites, Ceram. Int. 47 (2021) 9627-9634. https://doi.org/10.1016/j.ceramint.2020.12.101.

[41] I. FarahBakhsh, R. Antiochia, H.W. Jang, Pressureless sinterability study of ZrB2-SiC composites containing hexagonal BN and phenolic resin additives, Synth. Sinter. 1 (2021) 99-104. https://doi.org/10.53063/synsint.2021.1231.

[42] S.M. Arab, M. Shahedi Asl, M. Ghassemi Kakroudi, B. Salahimehr, K. Mahmoodipour, On the oxidation behavior of $\mathrm{ZrB} 2-\mathrm{SiC}-\mathrm{VC}$ composites, Int. J. Appl. Ceram. Technol. 18 (2021) 2306-2313. https://doi.org/10.1111/ijac.13858.

[43] L. Silvestroni, C. Melandri, V. Venkatachalam, J. Binner, D. Sciti, Merging toughness and oxidation resistance in a light $\mathrm{ZrB} 2$ composite, Mater. Des. 183 (2019) 108078. https://doi.org/10.1016/j.matdes.2019.108078.

[44]W.G. Fahrenholtz, Thermodynamic Analysis of ZrB2-SiC Oxidation: Formation of a SiC-Depleted Region, J. Am. Ceram. Soc. 90 (2007) 143-148. https://doi.org/10.1111/j.1551-2916.2006.01329.x.

[45] S. Torabi, Z. Valefi, N. Ehsani, The effect of the SiC content on the high duration erosion behavior of $\mathrm{SiC} / \mathrm{ZrB} 2-\mathrm{SiC} / \mathrm{ZrB} 2$ functionally gradient coating produced by shielding shrouded plasma spray method, Ceram. Int. 48 (2022) 1699-1714. https://doi.org/10.1016/j.ceramint.2021.09.249.

[46] Y.-J. Wang, H.-J. Li, Q.-G. Fu, H. Wu, D.-J. Yao, B.-B. Wei, Ablative property of $\mathrm{HfC}$-based multilayer coating for $\mathrm{C} / \mathrm{C}$ composites under oxy-acetylene torch, Appl. Surf. Sci. 257 (2011) 4760-4763. https://doi.org/10.1016/j.apsusc.2010.11.020.

[47] X. Zou, Q. Fu, L. Liu, H. Li, Y. Wang, X. Yao, Z. He, ZrB2-SiC coating to protect carbon/carbon composites against ablation, Surf. Coatings Technol. 226 (2013) 17-21. https://doi.org/10.1016/j.surfcoat.2013.03.027.

[48] X. Yao, H. Li, Y. Zhang, H. Wu, X. Qiang, A SiC-Si-ZrB2 multiphase oxidation protective ceramic coating for SiC-coated carbon/carbon composites, Ceram. Int. 38 (2012) 2095-2100. https://doi.org/10.1016/j.ceramint.2011.10.047.

[49] Q. Fu, Y. Shan, C. Cao, H. Li, K. Li, Oxidation and erosion resistant property of $\mathrm{SiC} / \mathrm{Si}-\mathrm{Mo}-\mathrm{Cr} / \mathrm{MoSi} 2$ multi-layer coated $\mathrm{C} / \mathrm{C}$ composites, Ceram. Int. 41 (2015) 4101-4107. https://doi.org/10.1016/j.ceramint.2014.11.105.

[50] T. Feng, H.-J. Li, Q.-G. Fu, X.-T. Shen, H. Wu, Microstructure and oxidation of multi-layer $\mathrm{MoSi} 2-\mathrm{CrSi} 2-\mathrm{Si}$ coatings for $\mathrm{SiC}$ coated carbon/carbon composites, Corros. Sci. 52 (2010) 3011-3017. https://doi.org/10.1016/j.corsci.2010.05.020.

[51] C.-S. Kim, T.R. Massa, G.S. Rohrer, Modeling the relationship between microstructural features and the strength of WC-Co composites, Int. J. Refract. Met. Hard Mater. 24 (2006) 89-100. https://doi.org/10.1016/j.ijrmhm.2005.04.011.

[52] T. Li, H. Li, X. Shi, Effect of LaB6 on the thermal shock property of MoSi2-SiC coating for carbon/carbon composites, Appl. Surf. Sci. 264 (2013) 88-93. https://doi.org/10.1016/j.apsusc.2012.09.124. 